\title{
Fascinating Giardia Lamblia and Vexing Chronic Spontaneous Urticaria: An Under-appreciated Association
}

\section{Mujtaba Hasan Siddiqui ${ }^{1}$ and lqbal Akhtar Khan ${ }^{2 *}$}

${ }^{1}$ Assistant Professor (Medicine), The University of Lahore Teaching Hospital, Defence Road, Lahore, Pakistan

${ }^{2}$ Independent Scholar, Lahore, Pakistan

*Corresponding author: Prof. Iqbal Akhtar Khan, MBBS DTM FACTM PhD, Lahore, Pakistan, E-mail: profiakhan@gmail.com

Received date: September 24, 2016; Accepted date: October 07, 2016; Published date: October 17, 2016

Copyright: (C) 2016 Siddiqui MH, et al. This is an open-access article distributed under the terms of the Creative Commons Attribution License, which permits unrestricted use, distribution, and reproduction in any medium, provided the original author and source are credited.

\begin{abstract}
Background: Chronic Spontaneous Urticaria (CSU) has been found to have a negative impact on all aspects of patients' lives - physical, mental, social and emotional. The ubiquitous and fascinating Giardia lamblia is primarily a gastrointestinal pathogen but it may present atypically (with or without gastroenterological manifestations). A link between Giardiasis and CSU was identified in the past. However, the possibility of this combination has been underappreciated in clinical practice, even in developed world, resulting in inordinate delay in reaching correct diagnosis and instituting targeted pharmacotherapy. Such a situation adds to the miseries of the patients, both mental anguish and physical suffering.
\end{abstract}

\section{Objectives:}

-To determine the role of Giardia lamblia in the causation of CSU

-To ratify the effects of eradication of Giardia lamblia on the course of CSU

Methods: The present study was conducted on 63 referred cases of CSU (with insignificant improvement from the treatment already instituted). In view of the possibility of concomitant Giardial infection stool microscopy was advised and three fresh stool specimens, taken on alternate days, were collected from every case and examined for parasites.

The two validated instruments employed for comparing Patient Related Outcome Measures (PROMs), before and after treatment, were UAS7 (Urticaria Activity Score of 7days) and CU-Q2oL (Chronic Urticaria Quality of Life Questionnaire).

Results: Twenty two percent of those tested were found to have sole infection with Giardia lamblia. Secnidazole Sodium, as a single oral dose, resulted in complete parasitological and clinical cure in $93 \%$ of the cases.

The results of the PROMs were compared and correlated with the clinical picture.

Conclusion: The effects of eradication of Giardia lamblia on the course of the urticaria were excellent. Complete resolution of symptoms was seen in $93 \%$ of cases (and no recurrence in the follow up period of 16 weeks) with specific anti-giardial therapy alone proving that the causative agent was Giardia lamblia and that there was no role for any concomitant dermatological pathology. There is a dire need for meaningful cooperation between specialists of Dermatology and Tropical Medicine, in the management of otherwise unexplained urticaria.

Keywords: Chronic spontaneous Urticaria; Giardia lamblia; Secnidazole; Patient reported outcome measures; Urticaria activity score; Chronic urticaria quality of life questionnaire; Health related quality of life

\section{Quote}

"The skin is the mirror of the intestinal tract; not only in the primary gastroenterological disorders one should look for dermatological complications but should also think in chronic skin lesions of concomitant intestinal alterations" [1].

\section{Introduction}

The first description of the clinical problem, now known as urticaria, can be traced to The Yellow Emperor's Classic of Internal Medicine (Huang Di Nei Jing 2698-2598 BCE) as "Feng Yin Zheng" which means wind type concealed rash [2,3]. In 1769 CE, Scottish Professor William Cullen coined the term "urticaria" which means transient oedematous papules, plaque with itching [4]. Since then remarkable work has been done in the classification and terminology of urticaria.

Chronic Spontaneous Urticaria (CSU) is defined as the recurrent development of transient wheals (hives), angioedema (AE), or both for 
more than 6 weeks, due to known or unknown causes [5]. It replaces the old term Chronic Idiopathic Urticaria (CIU) [6].

CSU, usually, lasts for 1 to 5 years. However, in up-to $40 \%$ of cases, it may last up to 10 years [7]. It is a vexing problem, a real "crux medicorum" as a cynic cited by Alan Feinberg said "I should rather see a tiger come into my office than a patient with chronic urticaria" [8]. Although frequently benign, it may sometimes be a red flag sign of serious internal disease [9]. Most cases occur at ages 20-40 years, the working age group [10]. Moreover, CSU has been found to have a negative impact on all aspects of the patient's life - physical, mental, social and emotional.

The first description of the presently known Giardia lamblia (also called $G$. intestinalis or $G$. duodenalis) is traced to Antony van Leeuwenhoek (1632-1723 CE), justifiably called "The Father of Protozoology", in his letter \# 34 dated 4th November 1681 CE addressed to Sir Robert Hooke, the then Secretary of the Royal Society of London. Interestingly, the organism has been found in human coprolites from European and American archeological sites [11]. This fascinating intestinal protozoan parasite, which can be found from tropics to Arctic Greenland, has no respect for age, sex, ethnicity or socio-economic status. It may infect neonates as early as 4 th postpartum day [12] and adults as old as 94 years [13]. This cosmopolitan pathogen constitutes a significant public health problem because of its high incidence and prevalence. It is one of the most common non-viral causes of diarrhoea, afflicting millions of individuals worldwide [14]. In the past, it has been relatively neglected partly due to the focus of the scientific community on more "fashionable diseases" [15]. However, in 2004, the World Health Organization included it in its Neglected Disease Initiative [14].

The symptomatology of Giardiasis is rich and the presentation diverse. It may present atypically (with or without gastroenterological features). Harris and Mitchell, in 1949, were the first to report Giardia lamblia associated urticaria that completely resolved after specific antigiardial therapy [16]. Since then numerous cases of allergic manifestations of this curious organism have been recorded from many parts of the world. In a study conducted, by Khan and Murtaza, in Pakistan, in 1998, on 57 individuals suffering from chronic urticaria, 13 (23\%) were found to harbour Giardia lamblia [17]. In another study, again in Pakistan in 2002, Giardia lamblia was detected in 43 (47\%) of the 92 cases presenting with chronic urticaria [18].

With this background knowledge, the present study was designed and conducted on proven cases of CSU. The objectives were:

- To determine the role of Giardia lamblia in the causation of CSU.

- To ratify the effects of eradication of Giardia lamblia, on the course of CSU.

\section{Patients and Methods}

\section{Study population}

Sixty three individuals (M:F 37:26), aged 20-78 years, with a history of urticaria of 6-28 weeks duration were enrolled in this study.

\section{Inclusion criteria:}

CSU cases diagnosed and treated by other health care providers (though without significant improvement) reporting to Adult Medicine
Clinic of the principal author during the period of August 2015 to July 2016.

Physician referred or self-referred.

Not investigated for Giardia lamblia.

\section{Exclusion criteria:}

Pregnant or lactating females

Although some of them had undergone non-specific blood tests, none was subjected to stool microscopy. To win the confidence of the patients, they were told that the cause of their urticaria may be an enteric parasitosis which could be diagnosed by stool examination.To minimize the dropout rate, the potential participants were given more than one health education session regarding anticipated benefits of the study. Informed consent was obtained after their free will to participate in the study.

\section{Study Instrument (Diagnostic Tool)}

\section{Laboratory analysis}

Stool microscopy was advised and three fresh stool specimens, taken on alternate days, collected from every case and examined for parasites.

\section{Confirming clinical diagnosis}

To augment the clinical diagnosis of CSU, all those with sole infection of Giardia lamblia ( $\mathrm{n}=14)$ were assessed by following two Patient Reported Outcome Measures (PROMs), and the baseline results recorded:

- UAS7

- $\mathrm{CU}-\mathrm{Q} 2 \mathrm{oL}$

\section{Assessment of urticaria activity and impact}

The disease activity was assessed by recording "Average Urticaria Score for 7 days (UAS7)". This is the daily number of wheals + daily intensity of pruritus $=$ daily UAS score for 7 days on a Likert type symptom intensity score (0-3) with a total daily score ranging from 0-6 (to a maximum of 42 in 7 days). Higher scores indicate greater severity [5].

\section{Evaluating urticaria specific quality of life (QoL)}

The measurement was done using the Chronic Urticaria Quality of Life Questionnaire (CUQ2oL) which consists of 23 questions/items grouped into 6 QoL categories associated with the disease: itch (2 questions), swelling (2 questions), activities (6 questions), sleep (5 questions), limitations (3 questions) and looks (5 questions). Each item has five responses (never, a little, somewhat, a lot, very much). The total score ranges from 0 to 100 ; higher scores indicate worse Q2oL [19].

To compare with the baseline results and to gauge the effectiveness of the targeted pharmacotherapy, the UAS7 and CU-Q2oL exercises were repeated for all the cases $(n=14))$ and the results recorded.

\section{Consensus Guidelines}

This term, used in the manuscript, denotes a joint initiative of: 
Dermatology Section of the European Academy of Allergy and Clinical Immunology (EAACI)

The EU-funded network of excellence

The Global Allergy and Asthma European Network (GA2 LEN)

The European Dermatology Forum (EDF)

The World Allergy Organization (WAO)

\section{Therapeutic Intervention}

From amongst the available therapeutic agents, Secnidazole Sodium was selected because it is very well tolerated and rapidly and completely absorbed after oral administration [20]. In the present study, it was administrated, under supervision, to all Giardia positive cases $(\mathrm{n}=14)$ as single oral dose with guaranteed compliance, in fact a "One Minute Treatment" [21].

\section{Results}

Nineteen of those tested were found to be positive for Giardia lamblia cysts. Five of these were excluded because of polyparasitism leaving 14 (M:F 9:5) solely harbouring Giardia lamblia. Their ages ranged from $24-78$ years.

All the cases $(n=14)$ were subjected to detailed history taking and clinical evaluation, for Giardiasis. Eight (57\%) denied any gastrointestinal symptoms during the entire course of the urticaria. However, the remaining $6(43 \%)$ admitted having varying levels of diarrhoea, abdominal discomfort, flatulence, anorexia and foul smelling bulky stools. A week after treatment all the cases $(n=14)$ were advised to have repeat stool microscopy to evaluate its effects. Thirteen (93\%) got a sustained parasitological cure. They were clinically monitored for the course of the urticaria. Within two weeks there was complete resolution of the cutaneous symptoms, which did not recur during the follow up period of sixteen weeks. The remaining patient, in whom the drug did not eradicate the Giardia, continued with his urticaria and was lost to follow up.

\section{Pre and Post-treatment evaluation of PROMs}

Pre-treatment: The mean baseline UAS7 score was 27 out of 42 whereas the CU-Q2oL score was 44 out of 100.

Post-treatment: The mean post-treatment UAS7 score was $<6$ out of 42 whereas the $\mathrm{Cu}-\mathrm{Q} 2 \mathrm{oL}$ score was $<10$ out of 100 .

\section{Discussion}

CSU is a vexing problem which has been found to have a negative impact on quality of life (QoL) which has been defined as the "the functional effects of a medical condition and/or its consequent therapy upon a patient, from the patient's perspective" [22]. Whereas the severity of disease is reasonably assessed by the UAS7 score, the health related impairment of quality of life (HR-QoL) is reliably gauged by the CU-Q2oL instrument. These are the two validated urticaria specific tools for PROMs. The treating physician has the choice to select either of the two or both. In the present study, both were used to augment the clinical diagnosis of urticaria, to compare the pre-treatment and posttreatment values and to ratify the effects of eradication of Giardia lamblia on the course of the urticaria.
The results of various published reports reveal a clear relationship between Giardial infection and allergy. Giacometti et al, from Italy, Ronellenfitsch et al. from Switzerland and Khan and Murtaza from Pakistan have observed a significant association between harbouring Giardia and allergic cutaneous manifestations [23-25]. In the Caracas (Venezuela) study of 1993, 18\% of the patients from the allergy clinic of the "Instituto de Biomedicina" were positive for Giardia lamblia. It was suggested that "the presence of this parasite enhances the sensitization towards antigens penetrating the intestinal mucosa" [26]. In another study by the same authors in $1998,70 \%$ of the patients infected with Giardia lamblia presented symptoms of allergy, in contrast to $43 \%$ of a non-Giardia parasitized group [27].

Alvarez-Guevara et al. from Cuba, succeeded in developing Giardine, an allergenic extract from Giardia lamblia, for demonstrating cutaneous sensitization to Giardia lamblia [28].

In case series of urticaria (positive for Giardia lamblia but without demonstrable gastrointestinal symptoms) Nenof from Germany [29], Weilhelm from the United States [30], Pietrzk from Poland [31] and Dogruman from Turkey [32] have reported that the eradication of Giardia lamblia resulted in complete resolution of cutaneous symptoms indicating that the cause of the urticaria was Giardia lamblia. Moreover, in some cases, urticaria returned on re-infection with Giardia lamblia, as confirmed by laboratory examination [30].

\section{Conclusion}

In the present study, the effects of eradication of Giardia lamblia on the course of urticaria, were excellent. Complete resolution of the cutaneous symptoms occurred in $93 \%$ of the cases (and no recurrence in the follow up period of 16 weeks) merely by specific pharmacotherapy proving that the incriminating organism was Giardia lamblia and there was no role for any concomitant dermatological pathology.

Kolkhir et al have suggested that "internal parasites should only be regarded as underlying cause of CSU when the treatment of parasitosis led to the eradication of the parasite and the remission of CSU" [33]. Both these conditions have been fulfilled in the present study; complete resolution of the urticarial symptoms with complete eradication of the incriminating parasite.

\section{Recommendations}

A noteworthy point is the frequent inordinate delay in identifying Giardial infection as the sole cause of urticaria. This could have two explanations:

The possibility was not considered, concentration being on more common causes.

The clinical symptoms were rarely suggestive of Giardiasis. This is especially true when the only manifestation of Giardiasis is cutaneous.

Whatever the reason for the delay in reaching the correct diagnosis and instituting targeted pharmacotherapy, the result adds to the miseries of the patient, both mental anguish and physical suffering. Here are some anecdotes reported for clinical interest. In a Polish study, a 31-year-old female patient (the physician herself) underwent sophisticated investigations for more than 10 weeks before Giardia was identified as the incriminating agent [31].

McKnight and Tetz, from the United States, reported a case under the care of a dermatologist, in whom cutaneous symptoms persisted 
for 32 weeks. Later on she was found to harbour Giardia lamblia, initially without gastrointestinal symptoms. After successful eradication of Giardia, the cutaneous symptoms completely resolved, not to recur in the follow up period of 18 months [34]. A 53-year-old man, with the sole complaint of urticaria of 36 weeks' duration, was reported from Germany. He was subjected to extensive and invasive investigations even those for malignancy. Eventually he proved to be a case of Giardiasis (cutaneous manifestation only without any gastroenterological symptoms). He was completely freed of the long standing problem simply by specific anti- giardial therapy [35].

There is a dire need for meaningful cooperation between specialists in Dermatology and Tropical Medicine in the management of patients with cutaneous manifestations. The possibility of Giardia lamblia should always be thought of in the differential diagnosis of otherwise unexplained urticaria. This advice, could save afflicted individuals from physical torment and mental anguish and from being an unnecessary burden on the healthcare system.

\section{Limitations of the Study}

Stool microscopy, being the easiest, safest, cheapest and traditional method was chosen as the study instrument. Since the faecal shedding of Giardia cysts is known to be inconsistent, varying from high to low with periods of negativity lasting as long as 2-30 days [36], three samples were taken on alternate days to increase the yield. However, even in experienced hands the sensitivity does not reach more than $90 \%$. Despite all this background knowledge, the available facilities and cost restraints precluded the use of alternative sophisticated diagnostic tools, such as copro-diagnosis and serology. The prevalence of Giardia lamblia, in the present study, is most probably an under-estimate.

Both Giardia lamblia and urticaria also occur in children and infants. Since the present study was conducted in an Adult Medicine Clinic, the results cannot necessarily be extrapolated to those units with populations from all age groups.

\section{Ethical Considerations}

The procedures adopted in the present study were in accordance with the 1975 Declaration of Helsinki, as reviewed in 1983.

\section{Source of Funding}

This research did not receive any specific grant from funding agencies in the public, commercial, or not-for-profit sectors.

\section{Conflict of Interest}

None

\section{Acknowledgements}

Many thanks to Prof. Marcus Maurer (Germany) for his helpful suggestions for improving the manuscript.The authors are very grateful to Dr. JP Miller (United Kingdom) for pre-submission critical review and editing the language.

\section{References}

1. Rosch W (1976) Manifestations of systemic diseases in the gastrointestinal tract. Fortschr Med 94: 405-409.
2. Veith I (1992) The Yellow Emperor's Classic of Internal Medicine. Malaysia Pelanduk Publications.

3. De-Hui S, Xiu-Fen W, Wang N (1995) Manual of Dermatology in Chinese Medicine. Eastland Press Seattle. 204-213.

4. Krupa Shankar DS, Ramnane M, Rajouria EA (2010) Etiological approach to chronic urticarial. Indian J Derm 55: 33-38.

5. Zuberbier T, Aberer W, Asero R, Bindslev-Jensen C, Brzoza Z, et al. (2014) The EAACI/GA(2)LEN/EDF/WAO Guidelines for the definition, classification, diagnosis, and management of urticaria: the 2013 revision and update. Allergy 69: 868-887.

6. Sussman G, Hebert J, Gulliver W, Lynde C, Waserman S, et al. (2015) Insights and advances in chronic urticaria:a Canadian perspective. Allergy Asthma Clin Immunolog 11: 1-7.

7. Negro-Alvarez JM, Miralles-Lopez JC (2001) Chronic idiopathic urticaria treatment. Allergol Immunopathol (Madr) 29: 129-132.

8. Tas J (1967) Chronic Urticaria: A Survey of 100 Hospitalized Cases. Dermatologica 135: 90- 96.

9. Sachdeva S, Gupta V, Amin SS, Tahseen M (2011) Chronic Urticaria. Indian J Derm 56: 622-628.

10. Caproni M, Volpi W, Giomi B, C Cardinali C, Antiga E, et al. (2004) Chronic idiopathic and chronic autoimmune urticaria: Clinical and Immunopathological features of 68 subjects. Acta Derm Venereol 84: 288-290.

11. Concalves ML, Araugo A, da Silva JP, Reinhard K, Bouchet F, et al. (2002) Detection of Giardia duodenalis antigen in coprolites using a commercially available enzyme- linked immunosorbent assay. Trans $\mathrm{R}$ Soc Trop Med Hyg 96: 640-643.

12. Farthing MJ, Mata L, Urrutia JJ, Kronmal RA (1986) Natural history of Giardia infection of infants and children in rural Guatemala and its impact on physical growth. Am J Clin Nutr 43: 395-405.

13. Cusack MA, O’Mahony MS, Woodhouse K (2001) Giardia in old people. Age and Ageing 30: 419-421.

14. Sovioli L, Smith H, Thompson A (2006) Giardia and Cryptosporidium join the "Neglected Disease Initiative". Trends Parasitol 22: 203-208.

15. Escobedo AA, Almirall P, Robertson LJ, Franco RM, Hanevik K, et al. (2010) Giardiasis: The Ever-Present Threat of a Neglected Disease. Infect Disord Drug Targets 10: 329-348.

16. Harris HR, Mitchell JH (1949) Chronic urticaria due to Giardia lamblia. Arch Dermatal Sphilology 59: 587-589.

17. Khan IA, Murtaza G (1999) Role of Giardia lamblia in the aetiopathogenesis of chronic urticarial. Medical Spectrum 20: 9-16.

18. Khan IA (2002) Allergic manifestations of common enteric Protozoa: Surgery of 100 cases. J Pak Assoc Derm 12: 3-9.

19. Stull DE, McBride D, Houghton K, Finlay AY, Gnanasakthy A, et al. (2016) Assessing Changes in Chronic Spontaneous/Idiopathic Urticaria: Comparison of Patient-Reported Outcomes Using Latent Growth Modeling. Adv Ther 33: 214-224.

20. Gillis JC, Wiseman LR (1996) Secnidazole: A review of its activity, pharmacokinetic properties and therapeutic use in the management of protozoan infections and bacterial vaginosis. Drugs 51: 621-638.

21. Siboulet A, Durel P (1961) A new 'one-minute'treatment of gonorrhea. Br J Vene Dis 37: 240-243.

22. Schipper H, Clinch J, Powell V (1990) Definitions and conceptual issues. In Spilker B editor. Quality of life assessment in clinical trials. New York. Raven Press: 11-24.

23. Giacometti A, Cirioni O, Antonicelli L,D’Amato G,Silvestri C, et al. (2003) Prevalence of intestinal parasites among individuals with allergic skin disease. J Parasitol 89: 490-492.

24. Ronellenfitsch U, Bircher A, Hatz C, Blum J (2007) Parasites as a cause of urticaria. Helminth and protozoa as triggers of hives? Hautarzt 58: 133-134.

25. Khan IA, Khan MA, Raza F, Khan SE (2010) A clinico epidemiological study of Giardiasis in children in Rural Punjab. J Muhammad Med Coll 1: 21-30. 
Citation: Siddiqui MH, Khan IA (2016) Fascinating Giardia Lamblia and Vexing Chronic Spontaneous Urticaria: An Under-appreciated Association. J Allergy Ther 7: 241. doi:10.4172/2155-6121.1000241

Page 5 of 5

26. Di Prisco MC, Hagel I, Lynch NR, Barrios RM, Alvarez N, et al. (1993) Possible relationship between allergic disease and infection by Giardia lamblia. Ann Allergy 70: 210-213.

27. Di Prisco MC, Hagel I, Lynch NR, Jimenez JC, Rojas R, et al. (1998) Association between Giardiasis and Allergy. Ann Allergy Asthma Immunol 81: 261-265.

28. Alvarez Guevara T, Alfonso Fernandez LA, Gomez Echevarria AH (1994) [Giardia lamblia extract (giardine): its immunologic mechanism]. Allergol Immunopathol (Madr) 22: 155-160.

29. Nenoff P, Domula E, Willing U, H Hermann J (2006) Giardia lamblia: Cause of urticaria and pruritis or accidental association?. Hautarzt 57: 518-522.

30. Wilhelm RE (1957) Urticaria associated with Giardiasis lamblia. J Aller Clin Immunol 28: 351-353.

31. Pietrzak A, Chodorowska G, Urban J, Bogucka V, Dybiec E (2005) Cutaneous manifestation of Giardiasis. Case Report. Ann Agric Environ Med 12: 299-303.
32. Dogruman Al F, Adisen E, Kustimur S, Guerer MA (2009) The role of protozoan parasites in etiology of urticaria. Turkie Parazitol Derg 33: 136-139.

33. Kolkhir P, Balakirski G, Merk HF, Olisova O, Maurer M (2016) Chronic spontaneous urticaria and internal parasites-A systematic review. Allergy 71: 308-322.

34. McKnight JT, Tietze PE (1992) Dermatologic manifestations of Giardiasis. J Am BoardFam Pract 5: 425-428.

35. Juergens UR, Predel HG, Vetter H (1989) Urticaria, Pruritis (Clinical Conference) Schweiz Rundsch Med Prax 78: 403-405.

36. Danciger M, Lopez M (1975) Numbers of Giardia in the feces of infected children. Am J Trop Med Hyg 24: 237-242. 